\title{
Advanced voltage control method for improving the voltage quality of low- voltage distribution networks with photovoltaic penetrations
}

\author{
Marika Nakamura ${ }^{1 *}$, Shinya Yoshizawa ${ }^{2}$, Hideo Ishii ${ }^{2}$ and Yasuhiro Hayashi ${ }^{1}$ \\ From 1st Energy Informatics.Academy Conference Asia \\ Beijing, China . 29-30 May 2021
}

\author{
* Correspondence: \\ 1998marika0101@ruri.waseda.jps \\ ${ }^{1}$ Department of Electrical \\ Engineering and Bioscience, School \\ of Advanced Science and \\ Engineering, Waseda University, \\ 3-4-1 Okubo, Shinjuku-ku, Tokyo \\ 169-8555, Japan \\ Full list of author information is \\ available at the end of the article
}

\begin{abstract}
As the number of photovoltaic (PV) power generators connected to the distribution grid increases, applications of on-load tap changers (OLTCS), power conditioning systems, and static reactive power compensators are being considered to mitigate the problem of voltage violation in low voltage distribution systems. The reactive power control by power conditioning systems and static reactive power compensators can mitigate steep voltage fluctuations. However, it creates losses in generation opportunities. On the other hand, OLTCs are installed at the bases of distribution lines and can collectively manage the entire system. However, the conventional voltage control method, i.e., the line drop compensation (LDC) method, is not designed for the case in which a large number of PV systems are installed in the distribution network, which results in voltage violations above the limit of the acceptable range. This study proposes a method to determine the optimal LDC control parameters of the voltage regulator, considering the power factor of PV systems to minimize the magnitude of voltage violations based on the voltage profile analysis of low-voltage (LV) distribution networks. Specifically, during a measurement period of several days, the voltages at some LV consumers and pole transformers were measured, and the optimal parameters were determined by analyzing the collected data. The effectiveness of the proposed method was verified through a numerical simulation study using the actual distribution system model under several scenarios of PV penetration rates. Additionally, the difference in the effectiveness of voltage violation reduction was verified in the case where all the LV consumer's consumer voltage data measured per minute were used as well as in the case where only the maximum and minimum values of the data within the measurement period were used. The results reveal that the proposed method, which operates within the parameters determined by the voltage analysis of the LV distribution network, is superior to the conventional method. Furthermore, it was found that even if only the maximum and minimum values of the measurement data were used, an effective voltage violation reduction could be expected.
\end{abstract}


Keywords: Voltage regulation, Vector LDC, Distribution networks, Photovoltaic networks, LV-network

\section{Introduction}

In recent years, photovoltaic (PV) power generation has garnered significant attention for achieving decarbonization, and the number of PV systems connected to distribution networks has been increasing worldwide. However, the high penetration of PV systems into distribution networks enhances voltage variation due to the reverse flow from PV systems during the daytime; the output of PV systems is affected by weather conditions, which frequently exhibit abrupt and unpredictable changes (Petinrin \& Shaabanb, 2010). Current distribution networks and conventional voltage control methods, including the line drop compensation (LDC) method, have not been designed to consider the integration of large numbers of PV systems. Therefore, voltage violations above the acceptable voltage limits occur. Distribution network operators must deploy countermeasures to overcome these PV-induced voltage violations and improve the voltage quality of the distribution networks incorporated into PV systems.

Several voltage control approaches for mitigating voltage violations have been proposed. In (Sam et al., 2014; Ali et al., 2017; Cagnano \& De Tuglie, 2015; Afshin et al., 2014; Weckx \& Driesen, 2016), control methods for reactive power injection from PV systems were developed. Although these methods respond rapidly to changes in PV generation, their voltage control performance depends on the allocation and capacity of the reactive power devices. This can lead to an increase in distribution loss due to excessive reactive power injection. In (Marra et al., 2013a; Marra et al., 2013b; Mossoba et al., 2010), PV systems were controlled in coordination with electric vehicles (EVs) to mitigate sudden voltage increases due to fluctuations in PV output. However, since the charging behavior of an EV is highly dependent on the owner's convenience, it is generally difficult to control the system as intended. Therefore, considering the minimization of PV generation suppression and the certainty of the control, it is desirable to maximize the use of voltage control devices that can be managed by the distribution network operator (DNO), such as on-load tap changers (OLTCs) and step voltage regulators (SVRs). Centralized control is a well-studied control method in voltage control using OLTC and SVRs. In the previous studies (Agalgaonkar et al., 2014; Azzouz \& ElSaadany, 2014; Kulmala et al., 2014), coordinated control using OLTC operation and reactive power injection from PV inverters were proposed to reduce distribution loss while regulating voltage. Other studies combined OLTCs and an energy storage system (ESS) (Xiaohu et al., 2012; Tewari et al., 2021) or PV power generation forecasts (Li et al., 2018). In (Li et al., 2018), voltage control schemes were proposed, which included an OLTC using voltage and current measurements obtained from sectionalizing switches with sensors in the distribution network. These methodologies require a highspeed communication infrastructure for online measurement and control as well as improved reliability against the risk of communication failures and delays. Another approach is the distributed control described in (Efkarpidis et al., 2016; Long \& Ochoa, 2016; Ranamuka et al., 2014). In (Efkarpidis et al., 2016), the active and reactive power control of PV inverters were coordinated whereas the capacitor banks were combined 
with OLTCs in (Long \& Ochoa, 2016) to keep the node voltage values within the permitted range in operation. OLTC and the distributed generations (DGs) cooperatively control the voltage by installing Volt/Var (Ranamuka et al., 2014) or LDC method (Muttaqi et al., 2015) on the DG. Other research describes a cooperative control of ESSs, distribution static compensators, and OLTCs (Houman et al., 2018). Contrary to the centralized control, these methods do not have to be accompanied by a communication infrastructure; however, as seen above, they need additional devices to implement voltage control.

This paper proposes an advanced voltage control method for an OLTC to minimize the voltage violation amount in LV distribution with PV systems by utilizing the voltage measurement information of smart meters, where neither communication facilities nor new equipment is required. In the proposed method, based on the voltage analysis of the limited LV distribution networks with PV systems, the control parameters are updated to mitigate the negative impacts of PV systems on distribution networks. The proposed voltage control method was tested on a model distribution network, which was created incorporating the parameters of the real network, and the voltage control performance was verified from the viewpoints of the voltage violation magnitude, the number of tap operations, and the total losses of the distribution network. In addition, it was found that the voltage violation reduction was significantly affected by which part of the entire information is used to derive the control parameters of an OLTC.

\section{Voltage control with the vector LDC method}

The voltage control scheme of the OLTC with the vector LDC method is shown in Fig. 1. In the vector LDC method, the tap position of the OLTC can be automatically changed based on the current through the OLTC to regulate the voltage at the reference point in the distribution network within a constant range (Vref $\pm \varepsilon$ ) (Efkarpidis et al., 2016). The voltage value at the reference point $V_{r}$ can be calculated from Eq. (1) from the sending voltage and current of the OLTC $\left(\dot{V}_{s}\right.$ and $\left.\dot{I}_{s}\right)$ and the impedance $(R$, $X)$ from the OLTC to the voltage reference point. Here, $V_{r}$ is obtained by vector calculation; thus, the OLTC can support the reverse power flow and adequately regulate the tap position.

$$
V_{r}=\left|\dot{V}_{s}-(R+j X) \dot{I}_{s}\right|
$$

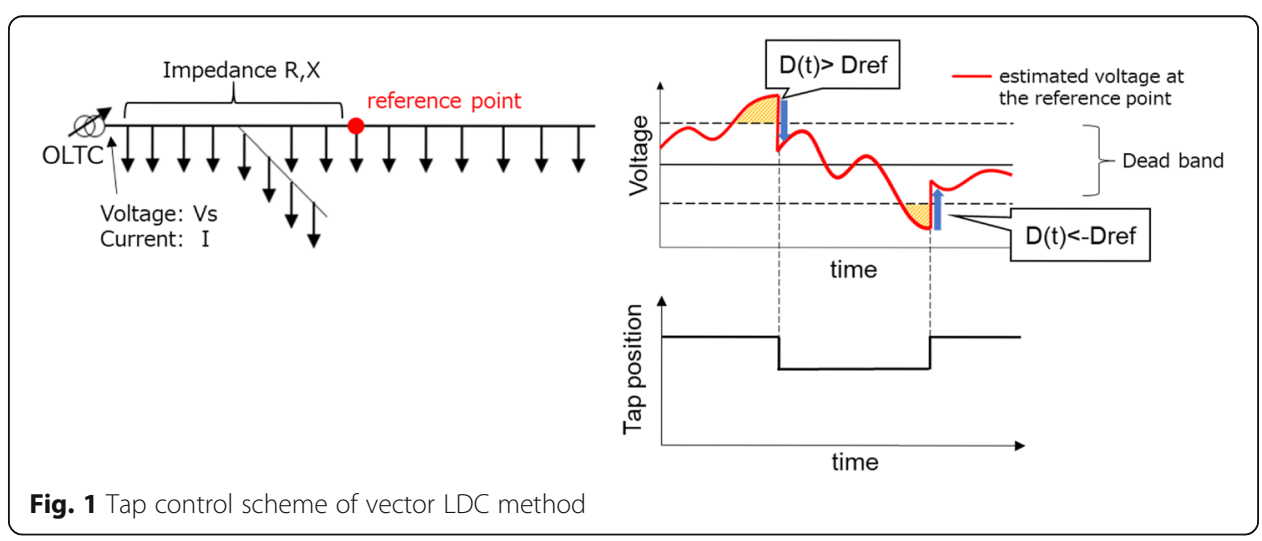


When $V_{r}$ violates from the dead band $\left(V_{r e f} \pm \varepsilon\right)$, the voltage difference between $V_{r}$ and the dead band is integrated as follows:

$$
D(t)=\left\{\begin{array}{cc}
\int\left\{V_{r}-\left(V_{r e f}+\varepsilon\right)\right\} d t, & \text { if } V_{r}>V_{r e f}+\varepsilon, \\
\int\left\{V_{r}-\left(V_{r e f}-\varepsilon\right)\right\} d t, & \text { if } V_{r}<V_{r e f}-\varepsilon \\
0 & \text { otherwise }
\end{array}\right.
$$

where $D(t)$ is the cumulative voltage difference from the dead band, $V_{r e f}$ is the target voltage, and $\varepsilon$ is the dead bandwidth. When $D(t)$ exceeds the time delay $D_{\text {ref }}$ the tap position $\operatorname{Tap}(t)$ is automatically changed to bring $V_{r}$ closer to $V_{r e f}$ and the cumulative voltage difference is reset to zero.

$$
\operatorname{Tap}(\mathrm{t})= \begin{cases}\operatorname{Tap}(t-1)-1, & \text { if } D(t)>D_{\text {ref }}, \\ \operatorname{Tap}(t-1)+1, & \text { if }(t)<-D_{\text {ref }}, \\ \operatorname{Tap}(t-1) & \text { otherwise, }\end{cases}
$$

\section{Conventional voltage control method}

For comparative analysis with the proposed method, the parameters of the conventional LDC control method were determined. The basic LDC parameters are determined to maintain the node voltage closer to the nominal voltage value without voltage violations in LV distribution networks without PV penetration. The formulation of the problem is shown in the following equations:

$$
\begin{aligned}
& \boldsymbol{x}_{\boldsymbol{b}}=\underset{\boldsymbol{x}}{\operatorname{argmin}} \sum_{n=1}^{N} \sum_{t=1}^{T}\left(M V_{t, n}(\boldsymbol{x})-1.0\right)^{2} \\
& \boldsymbol{x}=\left[V_{\text {ref }}, R, X\right] \\
& \text { s.t. } \\
& V_{\text {ref }}^{\text {min }} \leq V_{\text {ref }} \leq V_{\text {ref }}^{\max } \\
& 0 \leq R \leq R_{\text {max }} \\
& 0 \leq X \leq X_{\text {max }}
\end{aligned}
$$

where $M V_{t, n}(\boldsymbol{x})$ is the voltage at the MV node $n$ at time $t, L V_{t, j}(\boldsymbol{x})$ is the voltage at the $L V$-node $j$ at time $t$, and $L V_{L}$ and $L V_{U}$ are the lower and upper voltage limits, respectively. Also, $V_{r e f}^{\min }$ and $V_{\text {ref }}^{\max }$ are the lower and upper values of the search range of $V_{\text {ref }}$, respectively; $R_{\max } X_{\max }$ is the maximum LDC impedance; $N$ is the total number of MV nodes; and $T$ is the total number of time sections.

In addition, when determining the basic LDC parameters, it is confirmed that Eq. (9) is satisfied.

$$
L V_{L} \leq L V_{t, j}(\boldsymbol{x}) \leq L V_{U}
$$

\section{Proposed voltage control method}

\section{Overview of the proposed method}

In the proposed voltage control method, the target voltage $V_{r e f}$ is updated to mitigate voltage violations due to PV penetration in the LV distribution network, and the OLTC 
operates according to the updated LDC parameters. This proposed method assumes that some days of observation data using the basic LDC parameters are available when the power factor PF is changed to any value after the PV system has been penetrated.

Figure 2 shows an overview of the proposed voltage control method consisting of three steps: a) determination of permissible voltage limits in MV nodes, b) simulation of the MV voltage when changing the parameter, and c) determination of the optimal parameter.

\section{Determination of permissible voltage limits in MV distribution network}

Using the basic LDC parameters, voltage violations can be prevented when PV systems are not penetrated; however, voltages cannot be maintained within the permissible limits as the number of penetrated PV systems increases in LV distribution networks. In the LDC method, the OLTC operates according to the secondary voltage and current of the transformer to maintain the target voltage within a given range near the reference point in the MV distribution network. Therefore, in the normal LDC method, the LV distribution network conditions are not considered for the tap control. It is difficult to accurately estimate the voltage changes in the LV distribution network such as the voltage rise due to the reverse power flow. Thus, in the proposed method, the voltages in the LV voltage distribution networks with PV systems are analyzed using the basic LDC parameters, and the permissible voltage limits in the MV distribution network are determined based on the analyzed results. Using the basic LDC parameters, let $\Delta L V_{t, i, h, \widetilde{P F}}$ be the voltage drop from the pole transformer $i$ to each LV consumer $h$.

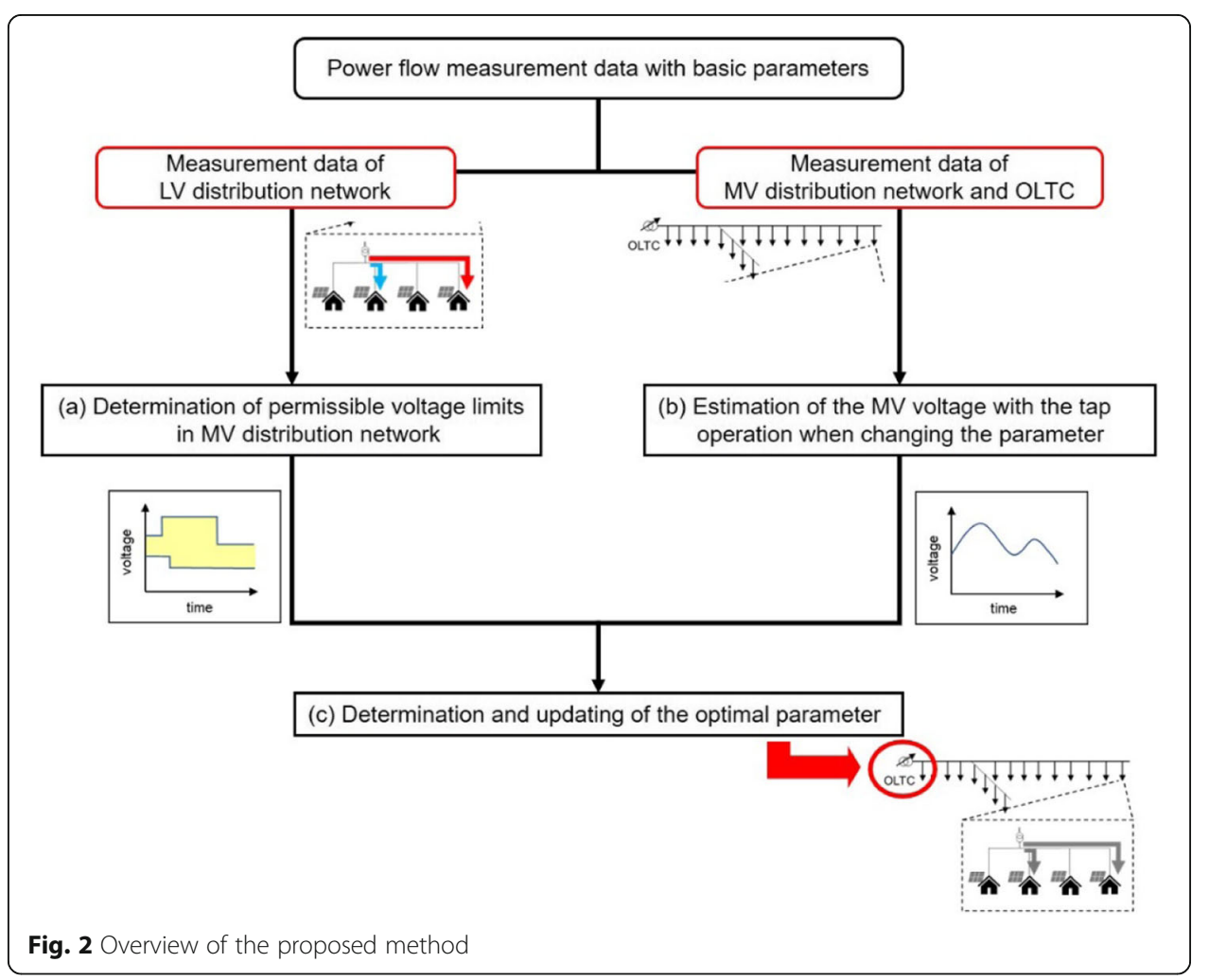


Then, the lower and upper voltage limits at the primary side of the pole transformer $i$ can be calculated according to the following equations:

$$
\begin{aligned}
& M V_{t, i, \widetilde{P F}}^{\min }=\left(L V_{L}+\max _{h \in H} \Delta L V_{t, i, h, \widetilde{P F}}\right) \times V_{\text {ratio }_{i}} \\
& M V_{t, i, \widetilde{P F}}^{\max }=\left(L V_{U}+\min _{h \in H} \Delta L V_{t, i, h, \widetilde{P F}}\right) \times V_{\text {ratio }_{i}}
\end{aligned}
$$

s.t.

$$
\widetilde{P F^{\text {min }}} \leq \widetilde{P F} \leq \widetilde{P F^{\max }}
$$

where $M V^{\min } \widetilde{\widetilde{P F}}$ and $M V_{t, i, \widetilde{P F}}^{\max }$ are the lower and upper voltage values, respectively, of the permissible voltage range of the pole transformer $i$ at time $t ; L V_{L}$ and $L V_{U}$ represent the permissible voltage limits at end-consumers; $V_{\text {ratio }}$ is the tap ratio of the pole transformer $i$; $H$ is the number of LV consumers connected to pole transformers $i$; and $\widetilde{P F^{\min }}$ and $\widetilde{P F^{\max }}$ are the upper and lower values of the search range of the power factor $\widetilde{P F}$, respectively.

\section{Estimation of the MV-voltage with tap operation when changing the LDC parameter}

In this step, the voltage profiles of the specific MV nodes are estimated when the vector LDC control parameter is changed. Here, to simplify and reduce computational costs, only $V_{\text {ref }}$ is updated.

First, the tap operation of the OLTC when changing the parameter is simulated based on the vector LDC method. As mentioned above, in the vector LDC method, the tap position is changed autonomically based on the voltage value of the reference point. Hence, before the simulation of the tap operation, the calculation of the voltage at the reference point that is not dependent on the tap position is needed and can be calculated by (13).

$$
V_{r_{t, \widetilde{P F}}}=V_{r_{t, \widetilde{P F}}}^{\text {base }}+\left(\operatorname{Tap}_{t, \widetilde{P F}}^{\text {base }}-\operatorname{Tap}_{\text {ini }}\right) * \text { Tap }_{\text {width }}
$$

where $V_{r_{t}, \widetilde{P F}}$ is the voltage at the reference point that does not depend on the tap pos-

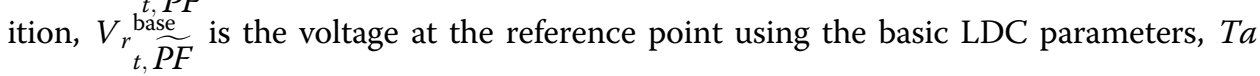
$p_{t, \widehat{P F}}^{\text {base }}$ is the tap position using the basic LDC parameters, Tap $p_{i n i}$ is the initial tap position, and Tap width is the tap width. Next, from the simulation result of the voltage at the reference point, the tap operation can be simulated by changing the parameters based on the vector LDC method. The equations of the simulation of the tap operation are shown below. When the tap position changes, the cumulative voltage difference $D(t$ $, \tilde{\boldsymbol{X}})$ is reset to zero.

$$
\begin{aligned}
& V_{r_{t}}^{\prime}(\tilde{\boldsymbol{X}})=V_{r t}+\left(\operatorname{Tap}_{t}(\tilde{\boldsymbol{X}})-\text { Tap }_{t}^{\text {base }}\right) * \operatorname{Tap}_{\text {width }} \\
& \operatorname{Violation}_{t}(\tilde{\boldsymbol{X}})=\left\{\begin{array}{c}
V_{r_{t}}^{\prime}(\tilde{\boldsymbol{X}})-\left(\widetilde{V_{r e f}}+\varepsilon\right), \text { if } V_{r_{t}}^{\prime}(\tilde{\boldsymbol{X}})>\widetilde{V_{r e f}}+\varepsilon \\
V_{r_{t}}^{\prime}(\tilde{\boldsymbol{X}})-\left(\widetilde{V_{r e f}}-\varepsilon\right), \text { if } V_{r_{t}}^{\prime}(\tilde{\boldsymbol{X}})<\widetilde{V_{r e f}}-\varepsilon
\end{array}\right.
\end{aligned}
$$




$$
\begin{aligned}
& D(t, \tilde{\boldsymbol{X}})=D(t-1, \tilde{\boldsymbol{X}})+\left(\text { Violation }_{t-1}(\tilde{\boldsymbol{X}})+\text { Violation }_{t}(\tilde{\boldsymbol{X}})\right) * \text { Time }_{\text {step }} / 2 \\
& \operatorname{Tap}(t, \tilde{\boldsymbol{X}})=\left\{\begin{array}{c}
\operatorname{Tap}(t-1, \tilde{\boldsymbol{X}})+1, \text { if } D(t, \tilde{\boldsymbol{X}})<-D_{\text {ref }} \\
\operatorname{Tap}(t-1, \tilde{\boldsymbol{X}})-1, \text { if } D(t, \tilde{\boldsymbol{X}})>D_{\text {ref }} \\
\operatorname{Tap}(t-1, \tilde{\boldsymbol{X}}), \text { otherwise }
\end{array}\right. \\
& \tilde{\boldsymbol{X}}=\left[\widetilde{P F}, \widetilde{V_{\text {ref }}}, R, X\right] \\
& \widetilde{V}_{V_{\text {ref }}^{\min } \leq \widetilde{V_{\text {ref }}} \leq \widetilde{V_{\text {ref }}^{\max }}}
\end{aligned}
$$

where $V_{r_{t}}^{\prime}(\tilde{\boldsymbol{X}})$ is the voltage at the reference point, Violation $_{t}(\tilde{\boldsymbol{X}})$ is the voltage violation of $\widetilde{V_{r e f}}$ from the dead band at time $t, D(t, \tilde{X})$ represents the cumulative voltage differ-

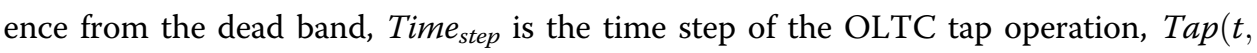
$\tilde{\boldsymbol{X}})$ is the tap position at time $t$, and $\widetilde{V_{r e f}^{\min }}$ and $\widetilde{V_{r e f}^{m a x}}$ are the lower and upper values of the search range of $\widetilde{V_{r e f}}$. From the estimation result of the tap operation, the voltage of the MV nodes can be calculated using Eq. (20):

$$
\mathrm{V}_{\mathrm{H}}^{\prime}(t, i, \tilde{\boldsymbol{X}})=\mathrm{V}_{\mathrm{H}}^{\text {base }}(t, i)+\left\{\operatorname{Tap}(t, \tilde{\boldsymbol{X}})-\operatorname{Tap}^{\text {base }}(t)\right\} * \operatorname{Tap}_{\text {width }}
$$

where $\mathrm{V}_{\mathrm{H}}^{\prime}(t, i, \tilde{X})$ is the primary voltage at the pole transformer $i$ when using parameters $\tilde{X}$ and $\mathrm{V}_{\mathrm{H}}^{\text {base }}(t, i)$ is the primary voltage at the pole transformer $i$ when using the basic LDC parameters.

\section{Determination of optimal parameters}

From the results of (a) and (b), the optimal parameters are determined. First, the amount of voltage violations exceeding the permissible voltage limits $\operatorname{Dev}_{t, i}(\tilde{\mathbf{X}})$ is calculated as shown below. Then, the $\tilde{X}$ with the smallest $\operatorname{Dev}_{t, i}(\tilde{\mathbf{X}})^{2}$ is the optimal combination of update parameters. When there are multiple $\tilde{X} \mathrm{~s}$ where $\operatorname{Dev}_{\mathrm{t}, \mathrm{i}}(\tilde{\mathbf{X}})^{2}$ is at the minimum, the parameter where the sum of squares of the distances from the median of the permissible voltage range, $\operatorname{Dis}_{t, i}(\tilde{\mathbf{X}})^{2}$, is at its minimum becomes the update parameter. The objective function is expressed as follows:

$$
\begin{aligned}
& \boldsymbol{X}=\underset{\boldsymbol{A}}{\operatorname{argmin}} \sum_{i=1}^{I} \sum_{t=1}^{T} D i s_{t, i}(\tilde{\boldsymbol{X}})^{2} \\
& \boldsymbol{A}=\left\{\widetilde{\boldsymbol{X}_{\boldsymbol{n}}}, \widetilde{\boldsymbol{X}_{\boldsymbol{n}+\mathbf{1}}, \cdots}, \widetilde{\boldsymbol{X}_{\boldsymbol{m}}}\right\}=\underset{\tilde{\boldsymbol{X}}}{\operatorname{argmin}} \sum_{i=1}^{I} \sum_{t=1}^{T} \operatorname{Dev}_{t, i}(\tilde{\boldsymbol{X}})^{2} \\
& \operatorname{Dev}_{t, i}(\tilde{\boldsymbol{X}})= \begin{cases}M V_{t, i, \widetilde{P F}}^{\min }-V_{H}^{\prime}(t, i, \tilde{\boldsymbol{X}}), & \text { if } M V_{t, i, \widetilde{P F}}^{\min }>V_{H}^{\prime}(t, i, \tilde{\boldsymbol{X}}), \\
V_{H}^{\prime}(t, i, \tilde{\boldsymbol{X}})-M V_{t, i, \widetilde{P F}}^{\max }, & \text { if } V_{H}^{\prime}(t, i, \tilde{\boldsymbol{X}})>M V_{t, i, \widetilde{P F}}^{\max } \\
0, & \text { otherwise }\end{cases} \\
& D i s_{t, i}(\tilde{\boldsymbol{X}})=V_{H}^{\prime}(t, i, \tilde{\boldsymbol{X}})-\left(M V_{t, i, \widetilde{P F}}^{\min }+M V_{t, i, \widetilde{P F}}^{\max }\right) / 2
\end{aligned}
$$

where $\boldsymbol{X}$ is the optimal combination of parameters, $\operatorname{Dis} s_{t, i}(\tilde{\boldsymbol{X}})$ is the distance from the 


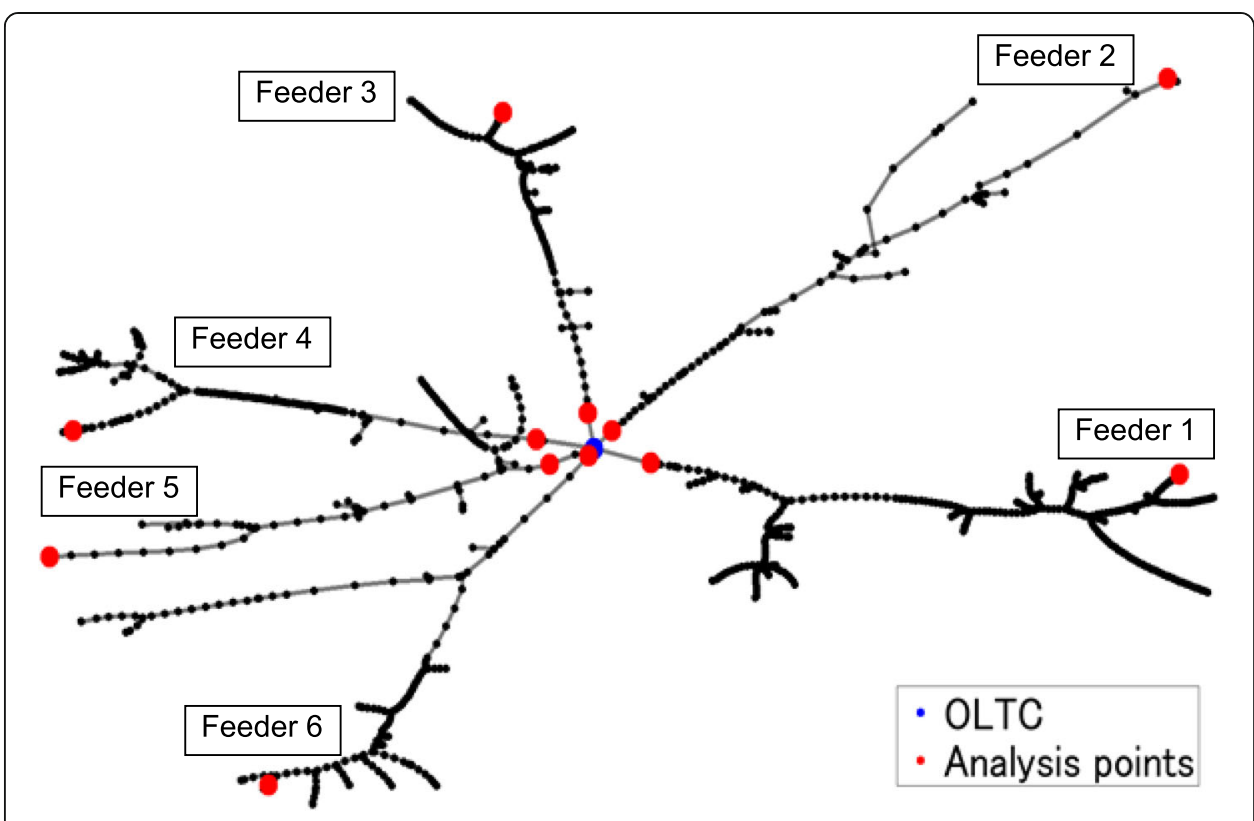

Fig. 3 Distribution network model

median of the permissible voltage range at the pole transformer $i$ at time $t, \operatorname{Dev}_{t, i}(\tilde{\boldsymbol{X}})$ is the voltage violation amount exceeding the permissible voltage limits, and $I$ is the total number of pole transformers in which the LV network is analyzed.

\section{Simulation conditions}

The distribution network model (Hayashi et al., 2018) used in the numerical simulation is shown in Fig. 3. The distribution network model has six MV distribution feeders extending from a distribution substation to supply electricity to $112 \mathrm{MV}$ consumers and 6057 LV consumers. The blue node in the figure indicates the location of the OLTC. This distribution network model is real, consisting of industrial and agricultural areas. Table 1 shows the length of the main line and the number of MV and LV consumers of each feeder.

We prepared different energy demand sets of 45 days, of which 15 days of data each were extracted during spring, summer, and winter to determine the LDC parameters. For MV demands, a dataset of 5 days in each season was used from the Energy Management System Open DATA by the Sustainable open Innovation Initiative (SII) (Sustainable open Innovation Initiative, Energy Management System Open DATA, 2021). For LV demand, the dataset of 5 days in each season was used from the actual measured data from the Japan New Energy and Industrial Technology Development

Table 1 Characteristics of each feeder

\begin{tabular}{|c|c|c|c|c|c|c|c|}
\hline & & Feeder 1 & Feeder 2 & Feeder 3 & Feeder 4 & Feeder 5 & Feeder 6 \\
\hline Length (km) & & 4.356 & 5.919 & 4.424 & 3.589 & 3.186 & 4.727 \\
\hline \multirow[t]{2}{*}{ Number of consumers } & MV & 28 & 17 & 14 & 21 & 14 & 18 \\
\hline & LV & 1951 & 705 & 1333 & 865 & 251 & 952 \\
\hline Industrial or Agricultural & & Agricultural & Agricultural & Agricultural & Industrial & Industrial & Industrial \\
\hline
\end{tabular}




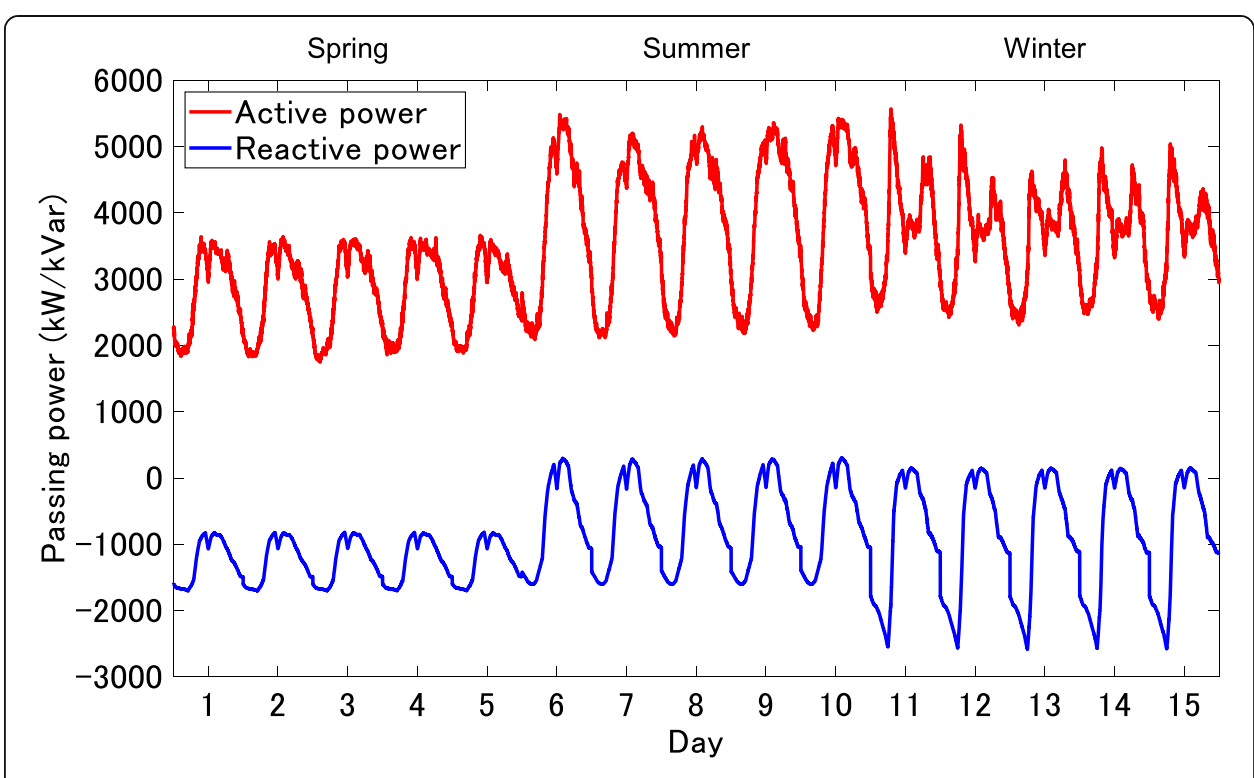

Fig. 4 Passing power through the distribution substation

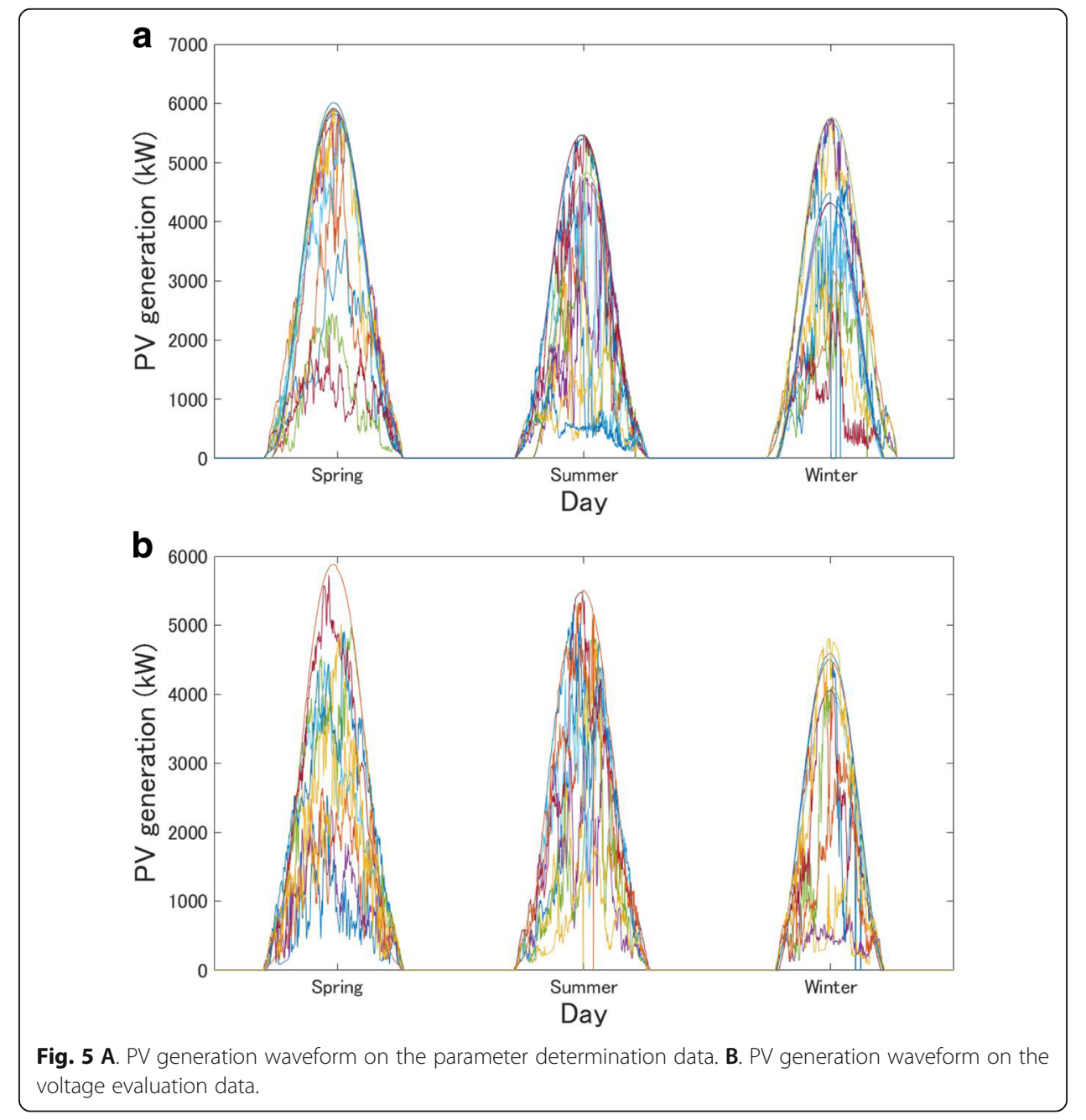


Table 2 the sum of PV generation amounts of each season (GW:s)

\begin{tabular}{llll}
\hline & Spring & Summer & Winter \\
\hline Parameter determination & 1177.3 & 1185.8 & 1154.5 \\
Voltage evaluation & 893.1 & 467.4 & 116.0 \\
\hline
\end{tabular}

Organization (NEDO) Ota City project (FY2002-FY2007) (Demonstrative research on Grid-interconnection of Clustered Photovoltaic Power Generation Systems, 2021).

Figure 4 shows the graph of the passing power through the distribution substation without PV systems. In other words, it shows the sum of the demand of MV consumers and LV consumers. From this graph, it can be said that the load demand in spring is light and the load demand in summer and winter is heavy.

For the PV profile, a dataset of 15 days per season was used from the actual measured data from the NEDO Ota City project (FY2002-FY2007) (Irradiation Database (2020) Neew Energy and Industrial Technology Development Organization, 2021). In the evaluation of the proposed method, PV waveforms for 30 days were prepared, which were different from those used when determining the LDC parameters. Figure 5 (A) and (B) shows the total PV generation waveforms on the parameter determination and voltage control evaluation data, and Table 2 shows the sum of PV generation for each season. As can be seen from these figures and the table, the PV output data was prepared for different weather conditions within the same season, and the differences between seasons can also be seen, with the highest power generation in spring and the lowest in winter.

In steps (a) and (b) of the proposed method, the points where the voltage permissible range and voltage profile were calculated (hereinafter referred to as the analysis points) are the 12 points indicated by red dots in Fig. 4. From the maximum impedance of the longest feeder of the distribution network model, $R_{\max }$ and $X_{\max }$ in Eq. (8) and Eq. (9) are set to $3.1626 \Omega$ and $3.1872 \Omega$, respectively. Table 3 shows the search range and step size of the target voltage and the power factor in the conventional and proposed methods. In the conventional method, the power factor is fixed at $95 \%$ and not optimized.

To evaluate the effectiveness of the proposed voltage control method, three simulation cases were considered based on different PV penetration ratios. In Case 1, the penetration ratio of the PV systems was $25 \%$ of the LV consumers. In Case 2, the penetration ratio was set to $50 \%$. In Case 3 , the penetration ratio was set to $75 \%$. In all cases, the PV systems penetrated sequentially from the end of the distribution feeders. The proposed method is compared to the conventional method, which controls the tap position based on the use of the basic LDC parameters (hereinafter called "PV0_opt").

We also prepared four different proposed methods, as shown in Table 4. Pro.1 and Pro.1_PF use only the minimum and maximum values among all the measurements of the voltage drop taken at the analysis points over 45 days, respectively. In other words,

Table $\mathbf{3}$ Search range and step size

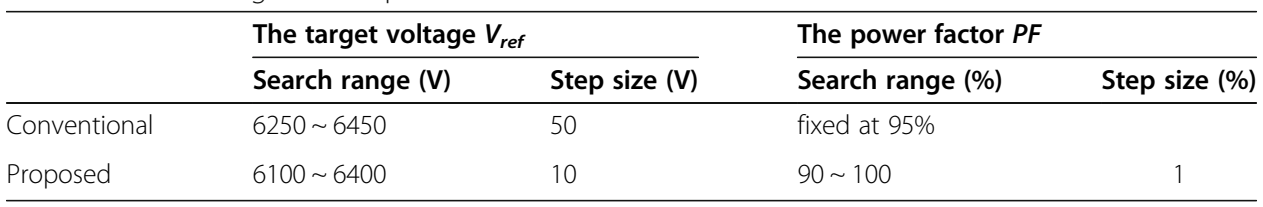


Table 4 Proposed methods

\begin{tabular}{lllll}
\hline & Pro.1 & Pro.1_PF & Pro.2 & Pro.2_PF \\
\hline Permissible range & Fixed for all time periods & \multicolumn{2}{l}{ Modified every time } \\
Optimization target & $V_{\text {ref }}$ & $V_{\text {ref }}$ and PF & $V_{\text {ref }}$ & $V_{\text {ref }}$ and PF \\
\hline
\end{tabular}

the minimum and maximum values of the voltage drop $\max _{h \in H} \Delta L V_{t, i, h}$ and $\min _{h \in H} \Delta L V_{t, i, h}$ and the permissible range of MV nodes calculated from them are fixed for all periods. On the other hand, in Pro.2 and Pro.2_PF, the acceptable ranges of the MV-nodes are modified by calculating the voltage drop every minute. In addition, in Pro.1 and Pro.2, we optimized only $V_{\text {ref }}$ by fixing the power factor of the power conditioning system (PCS) for the PV system at $95 \%$ as in the conventional case, while in Pro.1_PF and Pro.2_PF, both $V_{\text {ref }}$ and PF are optimized.

\section{Simulation results}

The determined "PV0_opt" parameters are shown in Table 5, and the determined $V_{\text {ref }}$ and $P F$ values for each case are shown in Table 6 and Table 7. Comparing between the cases, the optimal values of $V_{\text {ref }}$ and PF of all the proposed methods decrease as the PV penetration decreases.

Table 8 shows the results of the voltage violation amounts at all LV customers for 30 days for each method. Table 9 shows the results of the total voltage violation amounts at $12 \mathrm{LV}$ systems selected for analysis points. From Table 8, it is clear that in Cases 1 and 2, all the proposed methods could significantly reduce the voltage violation amounts compared to PV0_opt. On the other hand, in Case 3, where the PV penetration rate is high, Pro.1 and Pro.1_PF did not increase the voltage violation, but Pro.2 and Pro.2_PF deteriorated compared to PV0_opt. However, the results in Table 9 show that the voltage violation at the analysis point was extremely small in all the proposed methods. Furthermore, in Pro.2_PF, the voltage violation at the analysis point was avoided in all cases. This indicates that the voltage control performance can be improved using the proposed method that calculates the permissible range of MV nodes from the acquired data of the voltage drop at the LV system.

Figure 6 shows the voltage difference between the MV nodes and OLTC for each feeder on the day when the voltage violation amount was the largest in the PVO_opt operation. The vertical axis is the OLTC voltage value minus the voltage at each MV node, and a positive value means that a voltage drop is occurring. From this box-andwhisker diagram, we can see that feeder 1 has a large voltage drop, while feeders 2, 4, and 6 have frequent voltage rises. Therefore, in conjunction with the results in Table 8, it can be said that the proposed method is effective even in such a distribution system model where the voltage trend differs greatly among feeders.

The simulation results were also evaluated in terms of the number of tap operations and the total losses of the distribution system. Figure 7 depicts the total number of tap operations of the OLTC for 30 days for each method. The number of tap operations in

Table 5 Values of "PVO_opt" parameters

\begin{tabular}{llcc}
\hline$V_{\text {ref }}(\mathrm{V})$ & $\boldsymbol{R}(\Omega)$ & $\boldsymbol{X}(\Omega)$ & $P F(\%)$ \\
\hline 6350 & 0.0949 & 0.00 & 95 \\
\hline
\end{tabular}


Table $6 V_{\text {ref }}$ values of proposed methods $(V)$

\begin{tabular}{lllll}
\hline & Pro.1 & Pro.1_PF & Pro.2 & Pro.2_PF \\
\hline Case 1 & 6270 & 6290 & 6250 & 6250 \\
Case 2 & 6320 & 6320 & 6260 & 6250 \\
Case 3 & 6350 & 6350 & 6360 & 6320 \\
\hline
\end{tabular}

all cases did not significantly increase when using the proposed method. This indicates that the proposed method reduces voltage violations while properly operating the OLTC. In all cases, distribution losses did not significantly increase, as shown in Fig. 8, which depicts the total losses of the distribution network for 30 days. We conclude that the reactive power can be appropriately output using the proposed method.

Figure 9 is a bar chart of the voltage violation of the LV system in all proposed methods, where the positive and negative values indicate the violations from the upper and lower limits, respectively. In addition, Fig. 10 shows the permissible ranges at a specific analysis point calculated in Pro.1 and Pro.2 during the 45-day data acquisition period.

The comparison between the proposed methods shows that in Case 1, all methods are expected to reduce the voltage violation to almost the same level. However, in Cases 2 and 3, where the PV penetration ratio is higher, the proposed methods (Pro.1 and Pro.1_PF), which featured a fixed permissible range for all periods, performed better overall. As shown in Fig. 10, the permissible range of Pro.1 is narrower than that of Pro.2. In other word, Pro.1 optimized the parameters under more severe conditions. Therefore, in Pro.1, the parameter was selected where the voltage was less likely to violate even when the power flow changes. This is thought to be the reason the voltage violation in Pro.1 was smaller than that in Pro.2. Additionally, from this result, although it may be more desirable to measure the voltage every minute, sufficient reduction can be expected even if the collected data on the voltage drop provide only the minimum and maximum values.

We also compared the case where the value of $P F$ was fixed at $95 \%$ and the case where it was optimized. When $P F$ was optimized, the amount of voltage violation was smaller in Pro. 1 of Case 2 and Pro. 2 of Case 3, while it was worse in Pro. 1 of Case 1 and Pro.2 of Case 2. On the other hand, as shown in Tables 6 and 7, when PF was selected to be smaller, larger values of $V_{r e f}$ were selected, indicating that $P F$ was trying to decrease the voltage while $V_{r e f}$ was trying to increase it. This may be because the data used to determine the parameters is different from the data used in the evaluation, but it is necessary to be careful about how the parameters for unknown data are cooperatively selected.

With regard to the power factor of the PV PCS, the optimal power factor was set to be a large value as the PV penetration rate increases, as shown in Table 7. Figure 11 shows a box plot of the voltage drop from the OLTC to each MV node on a given day

Table 7 PF values of proposed methods (\%)

\begin{tabular}{lllll}
\hline & Pro.1 & Pro.1_PF & Pro.2 & Pro.2_PF \\
\hline Case 1 & 95 & 92 & 95 & 95 \\
Case 2 & 95 & 94 & 95 & 96 \\
Case 3 & 95 & 95 & 95 & 96 \\
\hline
\end{tabular}


Table 8 Voltage violation amounts at all LV consumers (V.min)

\begin{tabular}{llllll}
\hline & PV0_opt & Pro.1 & Pro.1_PF & Pro.2 & Pro.2_PF \\
\hline Case 1 & $1.19 e+04$ & 0.289 & 1.71 & 0.289 & 0.289 \\
Case 2 & 42.0 & 2.70 & 0 & 0.648 & 3.43 \\
Case 3 & 1.42 & 1.42 & 1.42 & 26.7 & 8.74 \\
\hline
\end{tabular}

Table 9 Voltage violation amounts at 12 analysis points (V.min)

\begin{tabular}{llllll}
\hline & PV0_opt & Pro.1 & Pro.1_PF & Pro.2 & Pro.2_PF \\
\hline Case 1 & 417 & 0 & 0 & 0 & 0 \\
Case 2 & 0.05 & 0 & 0 & 0 & 0 \\
Case 3 & 0.05 & 0.05 & 0.05 & 0.05 & 0 \\
\hline
\end{tabular}

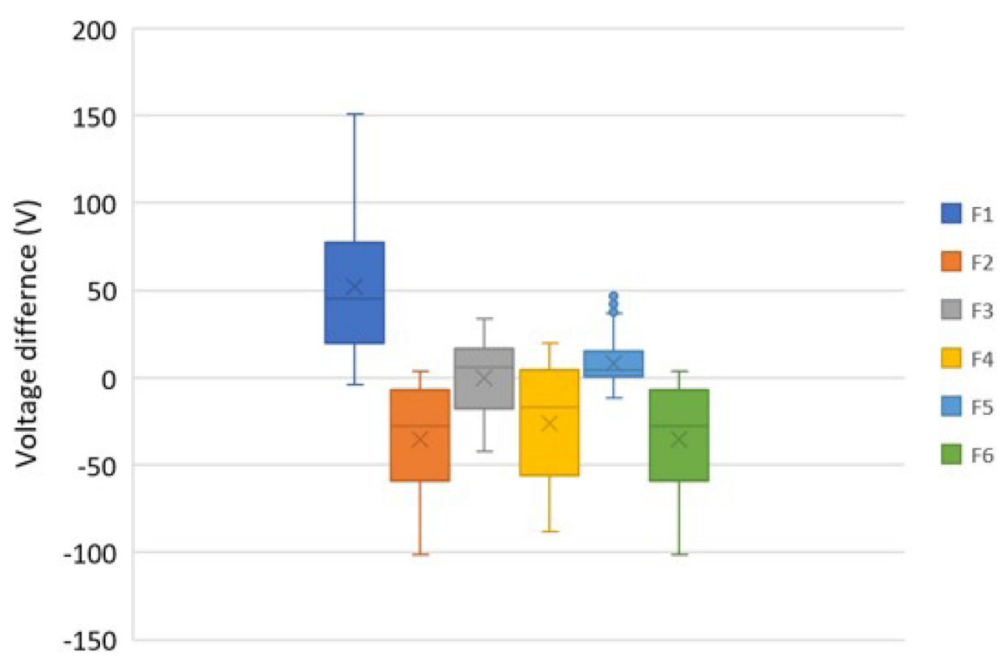

Fig. 6 Voltage difference between the MV nodes and OLTC for each feeder

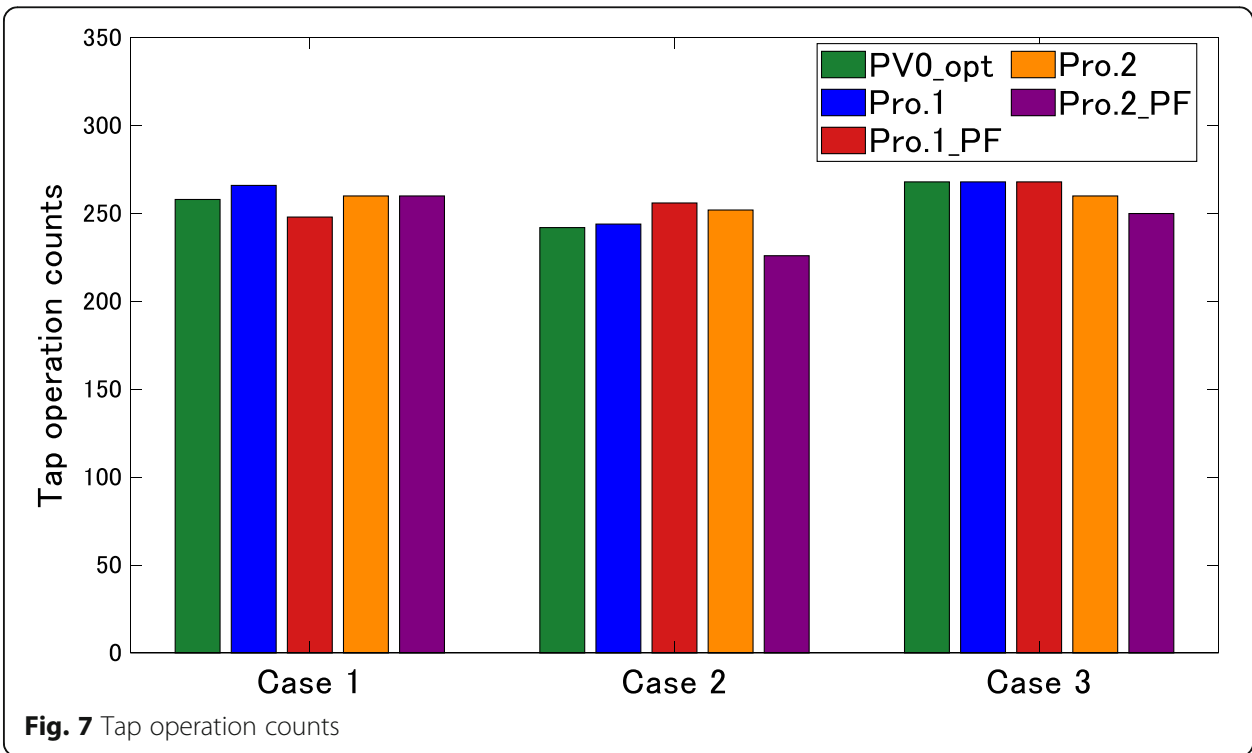




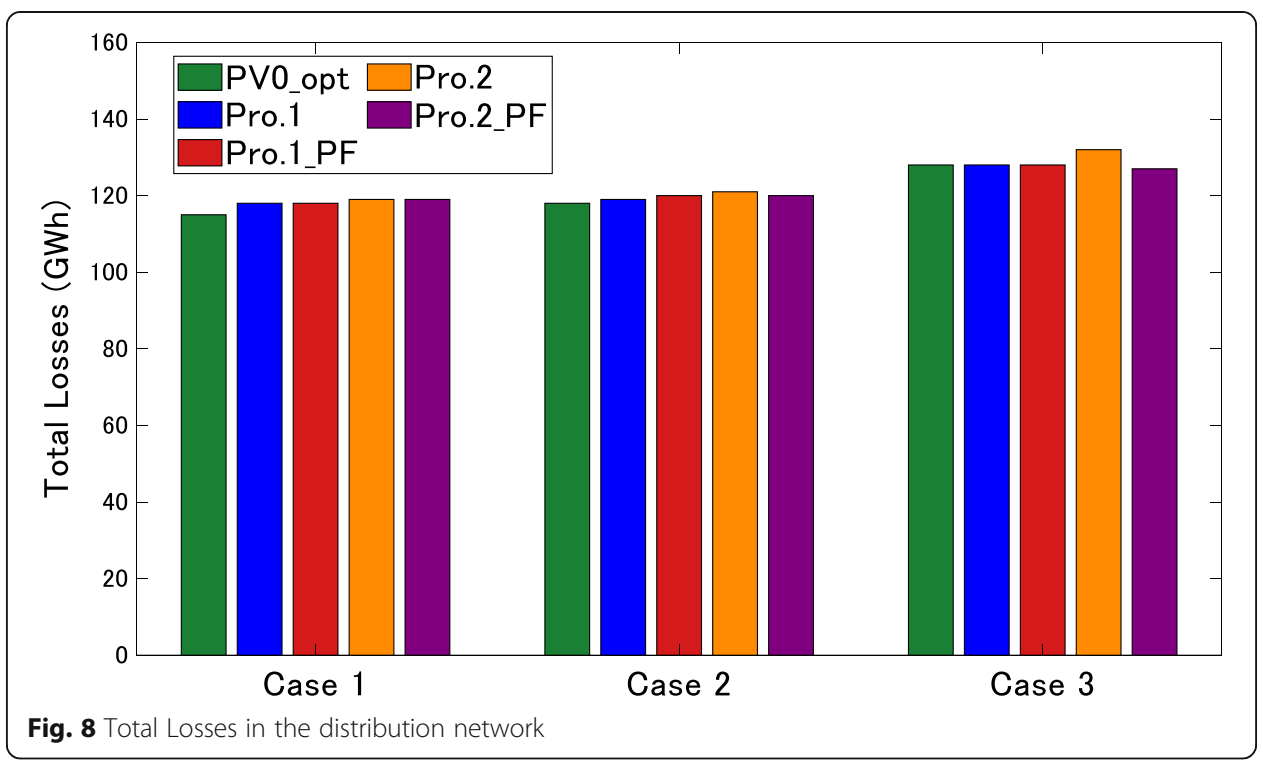

when PV0_opt was used. This box plot shows that in Case 3, the average value of the voltage drop is smaller than those in Cases 1 and 2, while the maximum value of the voltage drop is lower. Since OLTC manages all the MV nodes at once, the smaller the voltage difference among the MV nodes, the easier it is to manage using the OLTC. On the other hand, the smaller the PV penetration rate, the larger the voltage difference among the MV nodes. Therefore, the use of local voltage control is necessary by reducing the power factor in the earlier stage of PV penetration.

Figures 12(A) and (B) show the amount of active and reactive power passing through the OLTC on the same day, respectively. These graphs show that as the PV penetration rate increases, the amount of reactive power increases, while the amount of active power decreases for the entire distribution system at the same power factor value. The reverse power flow at OLTC was not seen even at the maximum PV ratio examined

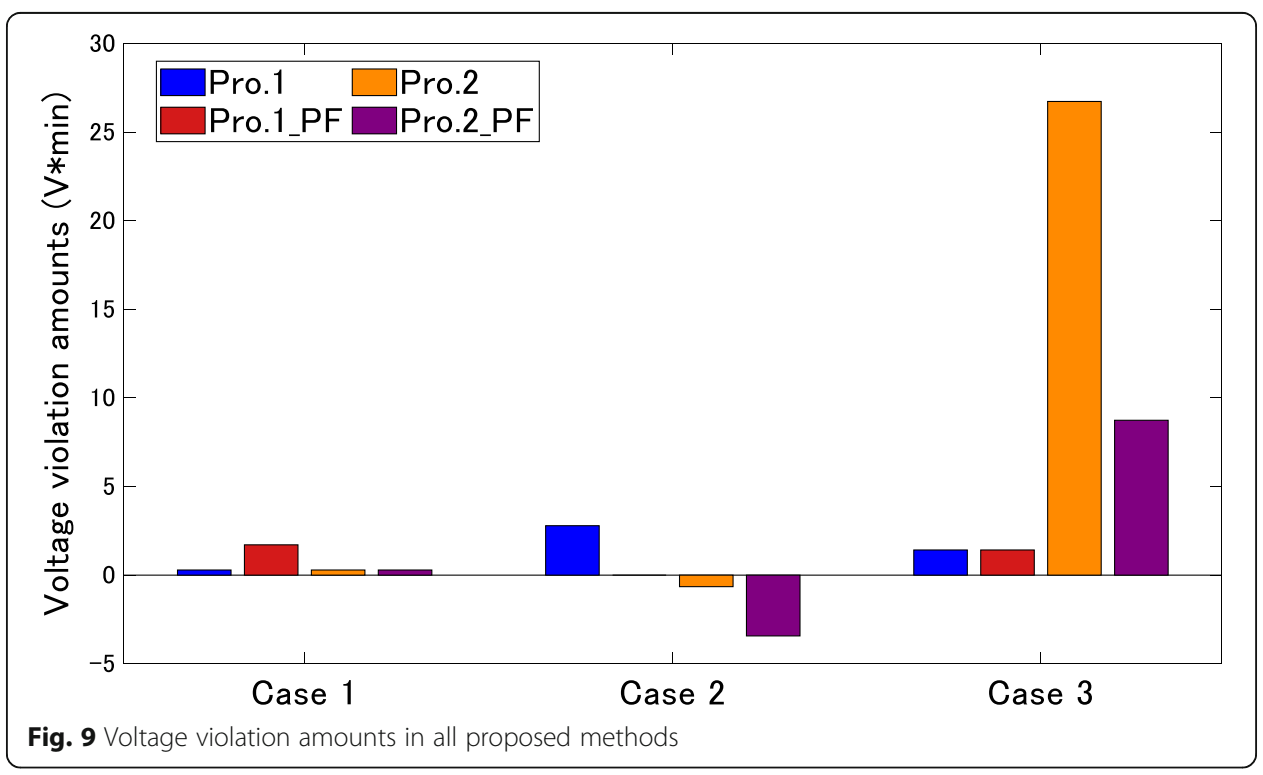




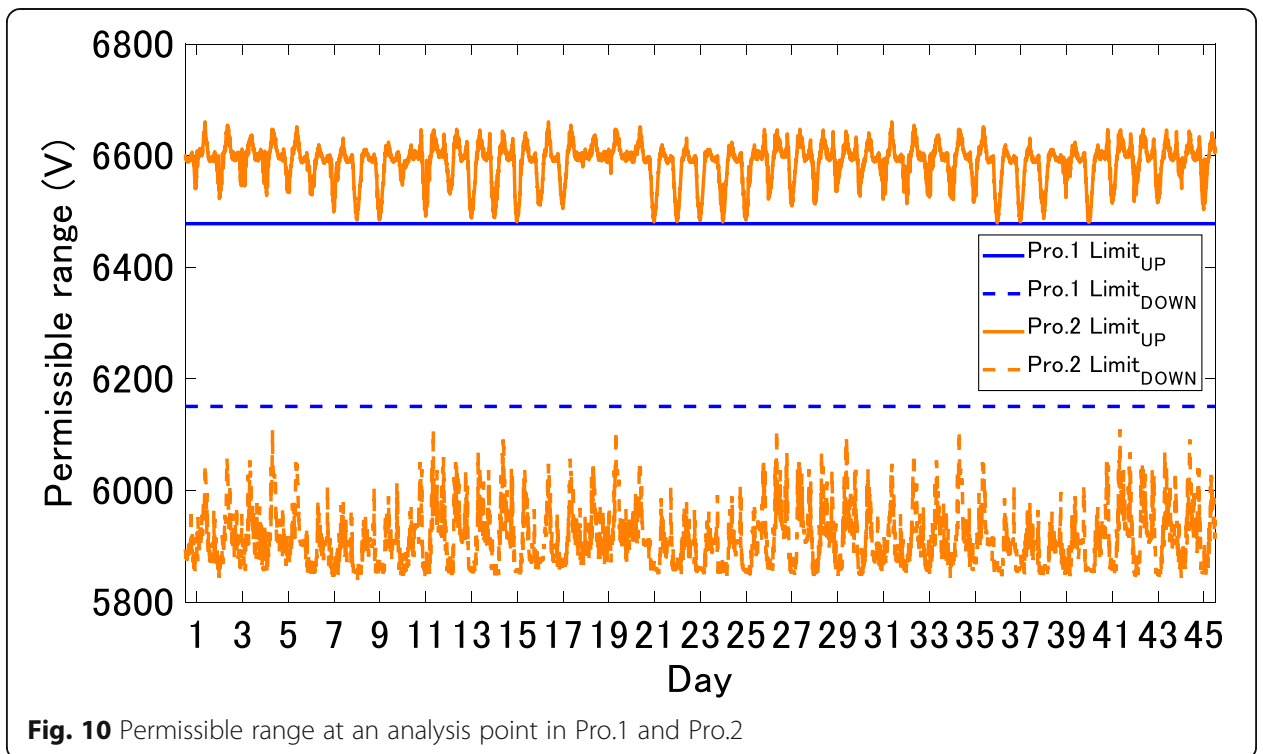

owing to large load in the distribution feeder. In addition, as shown in Fig. 11, a high PV ratio decreased the difference between the voltage of each MV node in this numerical simulation. Therefore, when the PV ratio is high, the control by the OLTC was relatively effective and the voltage violation could be avoided even with a larger power factor value (close to unity).

\section{Conclusions}

In this study, we proposed an advanced voltage control method of using on-load tap changers (OLTCs) for mitigating voltage violations in low voltage (LV) distribution due to photovoltaic (PV) penetrations. In the proposed method, the voltage control parameters of OLTCs and the power factor of the power conditioning subsystem (PCS) were determined based on the voltage analysis in the LV distribution network. The proposed

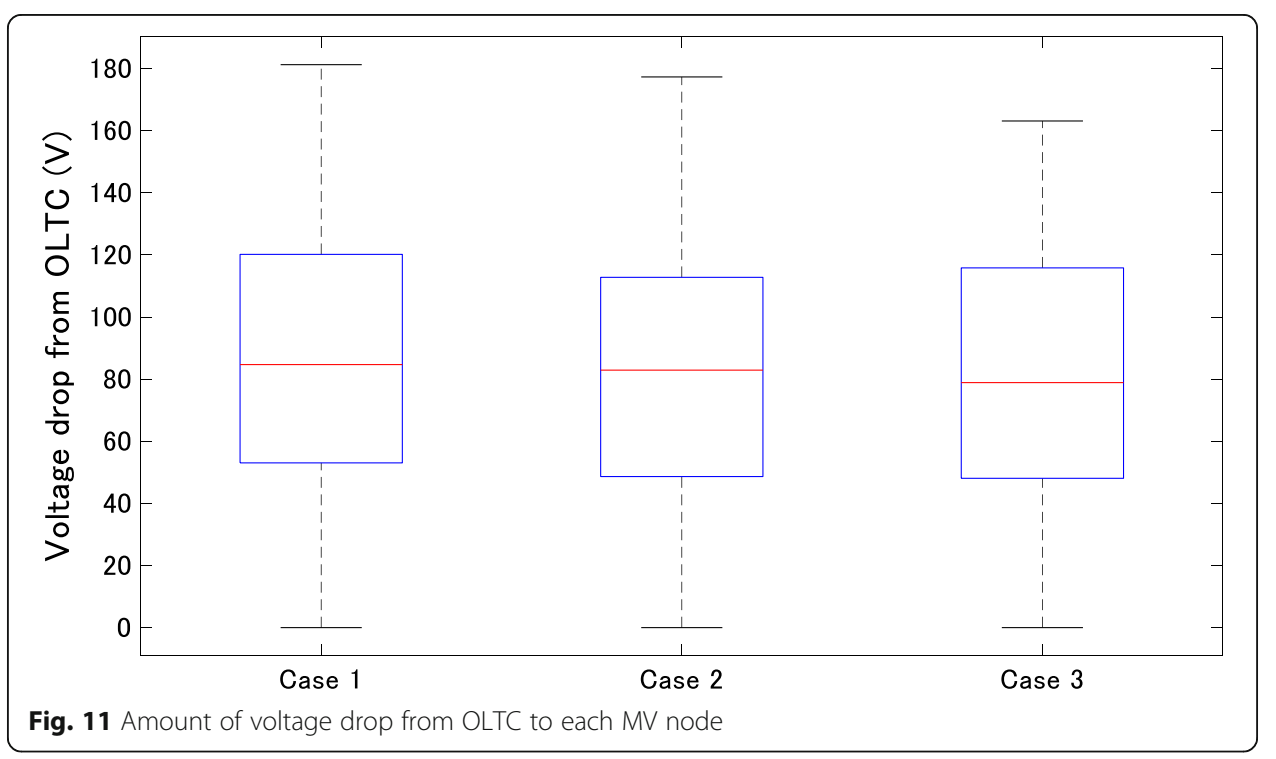




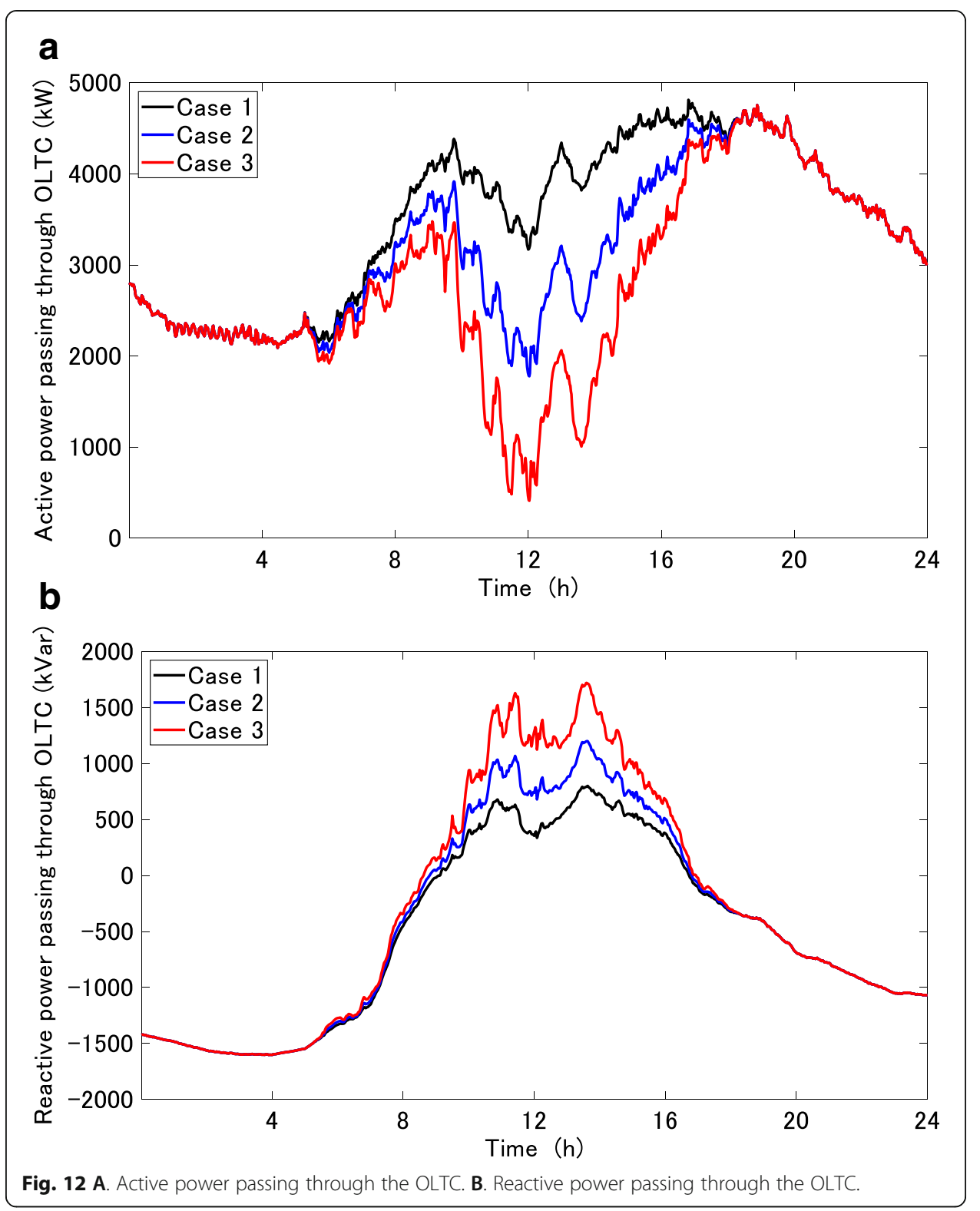

method was tested on a real distribution network model, and the results show that it can contribute to a reduction in voltage violations by calculating the permissible voltage range at middle voltage (MV) nodes from the obtained data. The results also show that Pro.1 and Pro.1_PF, which use only minimum and maximum values among the data of the voltage drop from the pole transformer, always contributed to the reduction of voltage violations. Therefore, we expect that the reduction effect will be sufficient even if only the minimum and maximum data are obtained. Furthermore, we found that the voltage violations were reduced even when the power factor was large because the voltage difference between each MV node decreases as the PV penetration rate increased.

However, there were some cases in which the voltage violation increased when the power factor was optimized. Therefore, care must be taken when parameters are cooperatively selected for the power factor and line drop compensation method. In the future, we will consider further determination methods of voltage control parameters, 
including the optimization of the LV distribution network locations where the voltage analysis is performed.

\section{Abbreviations}

ESS: Energy storage system; EV: Electric vehicle; DG: Distributed generation; DNO: Distribution network operator; LDC: Line drop compensation; LV: Low voltage; MV: Middle voltage; NEDO: New energy and industrial technology development organization; OLTC: On-load tap changer; PCS: Power conditioning subsystem; PV: Photovoltaic; SVC: Statics reactive power compensator; SVR: Step voltage regulator

\section{Acknowledgments}

This research is based on results obtained from a project (JPNP19002) commissioned by the New Energy and Industrial Technology Development Organization (NEDO). Moreover, we would like to thank Editage (http://www. editage.jp) for English language editing.

\section{About this supplement}

This article has been published as part of Energy Informatics Volume 4, Supplement 2 2021: Proceedings of the Energy Informatics.Academy Conference Asia 2021. The full contents of the supplement are available at https:// energyinformatics.springeropen.com/articles/supplements/volume-4-supplement-2.

\section{Authors' contributions}

MN ran the power flow calculations and analyzed the results. SY built the phylogenetic model and worked with MN on the scheme of the proposed method. HI improved the proposed method and contributed greatly to the writing of the manuscript. YH provided scientific support during the research activities. All authors confirmed and approved the final manuscript.

\section{Funding}

This work is part of the project (JPNP19002) funded by the New Energy Industrial Technology Development Organization (NEDO), Japan.

\section{Availability of data and materials}

The use of the demand data of low voltage consumers can be applied for at https://www.nedo.go.jp/activities/ZZ_ 00229.html, and the data regarding the middle voltage consumers demand can be found at https://www.emsopendata.jp/. For the PV profile, the dataset was prepared based on https://www.nedo.go.jp/library/nissharyou.html.

\section{Declarations}

\section{Ethics approval and consent to participate}

Not applicable.

\section{Consent for publication}

Not applicable.

\section{Competing interests}

The authors declare that they have no competing interests.

\section{Author details}

${ }^{1}$ Department of Electrical Engineering and Bioscience, School of Advanced Science and Engineering, Waseda University, 3-4-1 Okubo, Shinjuku-ku, Tokyo 169-8555, Japan. ${ }^{2}$ Advanced Collaborative Research Organization for Smart Society, Waseda University, 1-6-1 Nishi-Waseda, Shinjuku-ku, Tokyo, Japan.

\section{Published: 24 September 2021}

\section{References}

Afshin S, Robert E, Lennart S, Rawn BG, Boemer JC (2014) Coordinated active power-dependent voltage regulation in distribution grids with PV systems. IEEE Trans Power Deliv. 29(3):1454-1464. https://doi.org/10.1109/TPWRD.2014.2298614

Agalgaonkar YP, Pal BC, Jabr RA (2014) Distribution voltage control considering the impact of PV generation on tap changers and autonomous regulators. IEEE Trans Power Syst 29(1):182-192. https://doi.org/10.1109/TPWRS.2013.2279721

Ali S, Poria F, lqbal H (2017) Reactive power Management for Overvoltage Prevention at high PV penetration in a low-voltage distribution system. IEEE Trans Ind Appl 53(6):5786-5794. https://doi.org/10.1109/TIA.2017.2741925

Azzouz MA, El-Saadany EF (2014) Optimal coordinated volt/Nar control in active distribution networks. 2014 IEEE PES general meeting | Conference \& Exposition. 1-5. doi:https://doi.org/10.1109/PESGM.2014.6939137

Cagnano A, De Tuglie E (2015) Centralized voltage control for distribution networks with embedded PV systems. Renew Energy 76:173-185. https://doi.org/10.1016/j.renene.2014.11.015

Demonstrative research on Grid-interconnection of Clustered Photovoltaic Power Generation Systems. New Energy and Industrial Technology Development Organization. https://www.nedo.go.jp/activities/ZZ_00229.html. Accessed 18 May 2021

Efkarpidis N, Rybel TD, Driesen J (2016) Technical assessment of centralized and localized voltage control strategies in low voltage networks. Sustainable Energ Grid Netw 8:85-97. https://doi.org/10.1016/j.segan.2016.09.003

Hayashi Y, Fujimoto Y, Ishii H, Takenobu Y, Kikusato H, Yoshizawa S, Amano Y, Tanabe SI, Yamaguchi Y, Shimoda Y, Yoshinaga J (2018) Versatile modeling platform for cooperative energy management systems in smart cities. Proc IEEE 106(4):594612. https://doi.org/10.1109/JPROC.2018.2809468 
Houman P, Ali A, Gerard L, Peter W (2018) Probabilistic voltage management using OLTC and dSTATCOM in distribution networks. IEEE Trans Power Deliv 33(2):570-580. https://doi.org/10.1109/TPWRD.2017.2718511

Irradiation Database (2020) Neew Energy and Industrial Technology Development Organization. https://www.nedo.go.jp/libra ry/nissharyou.html. Accessed 18 May 2021

Kulmala A, Repo S, Järventausta P (2014) Coordinated voltage control in distribution networks including several distributed energy resources. IEEE Trans Smart Grid 5(4):2010-2020. https://doi.org/10.1109/TSG.2014.2297971

Li C, Disfani VR, Pecenak ZK, Mohajeryami S, Kleissl J (2018) Optimal OLTC voltage control scheme to enable high solar penetrations. Electr Power Syst Res 160:318-326. https://doi.org/10.1016/j.epsr.2018.02.016

Long C, Ochoa LF (2016) Voltage control of PV-rich LV networks: OLTC-fitted transformer and capacitor banks. IEEE Trans Power Syst 31(5):4016-4025. https://doi.org/10.1109/TPWRS.2015.2494627

Marra F, Yang GY, Fawzy YT, Traeholt C, Larsen E, Garcia-Valle R, Jensen MM (2013a) Improvement of local voltage in feeders with photovoltaic using electric vehicles. IEEE Trans Power Syst. 28(3):3515-3516. https://doi.org/10.1109/TPWRS.2013.224 8959

Marra F, Yang GY, Traeholt C, Larsen E, Ostergaard J, Blazic B, Deprez W (2013b) EV charging facilities and their application in LV feeders with photovoltaics. IEEE Trans Smart Grid 4(3):1533-1540. https://doi.org/10.1109/TSG.2013.2271489

Mossoba J, llic M, Casey L (2010) PV plant intermittency mitigation using constant DC voltage PV and EV battery storage. IEEE Conf Innovative Technol Efficient Reliable Electricity Supply:297-301. https://doi.org/10.1109/CITRES.2010.5619791

Muttaqi KM, Le ADT, Negnevitsky M, Ledwich G (2015) A coordinated voltage control approach for coordination of OLTC, voltage regulator, and DG to regulate voltage in a distribution feeder. IEEE Trans Ind Appl 51(2):1239-1248. https://doi. org/10.1109/TIA.2014.2354738

Petinrin JO, Shaabanb M (2010) Impact of renewable generation on voltage control in distribution systems. Renew Sust Energ Rev 65:770-783. https://doi.org/10.1016/j.rser.2016.06.073

Ranamuka D, Agalgaonkar AP, Muttaqi KM (2014) Dynamic adjustment of OLTC parameters using voltage sensitivity while utilizing DG for volt/NAr support. IEEE PES general meeting | Conference \& Exposition, IEEE. 1-5. doi:https://doi.org/10.11 09/PESGM.2014.6939808

Sam W, Carlos G, Johan D (2014) Combined central and local active and reactive power control of PV inverters. IEEE Trans Sustain Energy. 5(3):776-784. https://doi.org/10.1109/TSTE.2014.2300934

Sustainable open Innovation Initiative, Energy Management System Open DATA. https://www.ems-opendata.jp/. Accessed 18 May 2021

Tewari T, Mohapatra A, Anand S (2021) Coordinated control of OLTC and energy storage for voltage regulation in distribution network with high PV penetration. IEEE Trans Sustainable Energy 12(1):262-272. https://doi.org/10.1109/ TSTE.2020.2991017

Weckx S, Driesen J (2016) Optimal local reactive power control by PV inverters. IEEE Trans Sustain Energy 7(4):1624-1633. https://doi.org/10.1109/TSTE.2016.2572162

Xiaohu L, Aichhorn A, Liming L, Hui L (2012) Coordinated control of distributed energy storage system with tap changer transformers for voltage rise mitigation under high photovoltaic penetration. IEEE Trans Smart Grid 3(2):897-906. https:// doi.org/10.1109/TSG.2011.2177501

\section{Publisher's Note}

Springer Nature remains neutral with regard to jurisdictional claims in published maps and institutional affiliations.

\section{Submit your manuscript to a SpringerOpen ${ }^{\circ}$ journal and benefit from:}

- Convenient online submission

- Rigorous peer review

- Open access: articles freely available online

- High visibility within the field

- Retaining the copyright to your article

Submit your next manuscript at $\boldsymbol{\nabla}$ springeropen.com 